COMUNICAÇÃO CIENTÍFICA

\title{
CONTROLE PÓS-COLHEITA DA ANTRACNOSE DO MARACUJAZEIRO- AMARELO COM APLICAÇÃO DE ÓLEO DE COPAÍBA ${ }^{1}$
}

\author{
SEBASTIÃO ELVIRO DE ARAÚJO NETO², WAGNER DE MOURA FRANCISCO ${ }^{3}$, \\ ROMEU DE CARVALHO ANDRADE NETO ${ }^{4}$, CAMILA LUSTOSA ${ }^{5}$, \\ SANDRA ALBUQUERQUE LIMA RIBEIRO ${ }^{6}$
}

RESUMO - O objetivo deste trabalho foi avaliar a aplicação de óleo essencial de copaíba no controle da antracnose, nos frutos do maracujazeiro-amarelo, e comparar sua ação fungicida/fungistática in vitro com o óleo resina de copaíba. No experimento in vivo, os frutos foram inoculados com uma suspensão de esporos da ordem de $10^{6}$ conídios $\mathrm{mL}^{-1}$ e $1 \%$ de Tween 80 , acondicionados em bandejas de polipropileno e colocados em câmara incubadora com temperatura de $25^{\circ} \mathrm{C}$ e $90 \%$ de umidade relativa do ar. Passadas 24 horas da inoculação, pulverizou-se óleo essencial nas seguintes concentrações: T1 $=0 \mathrm{~mL} \mathrm{~L}{ }^{-1}$; T2 $=0,25 \mathrm{~mL}$ $\mathrm{L}^{-1} ; \mathrm{T} 3=0,5 \mathrm{~mL} \mathrm{~L}^{-1} ; \mathrm{T} 4=0,75 \mathrm{~mL} \mathrm{~L}^{-1} ; \mathrm{T} 5=1,0 \mathrm{~mL} \mathrm{~L}^{-1}$, sendo avaliados a perda de massa do fruto, a severidade da antracnose e o número de lesões, ambas aos seis dias. Para o experimento in vitro, utilizou-se do meio de cultura batata-dextrose-ágar (BDA) que, após ser esterilizado em autoclave $\left(120^{\circ} \mathrm{C}\right)$, recebeu óleo essencial e óleo resina de copaíba $\left(0 ; 0,5 ; 1,0 ; 1,5\right.$ e 2,0 $\left.\mathrm{mL} \mathrm{L}^{-1}\right)$. Após o resfriamento do meio de cultura, foi repicado para o centro da placa um disco de micélio de 12,5 mm de diâmetro de Colletotrichum gloeosporioides; e as placas, incubadas a $25^{\circ} \mathrm{C}$ e $90 \%$ de umidade. A aferição do crescimento micelial foi verificada com o auxílio de paquímetro analógico, após sete dias de crescimento micelial. O óleo essencial de copaíba, nas concentrações de $0,25 \mathrm{~mL} \mathrm{~L}^{-1}$ a $1.0 \mathrm{~mL} \mathrm{~L}^{-1}$, não foi eficaz no controle pós-colheita do fungo da antracnose in vivo e na perda de massa dos frutos de maracujá. O óleo resina de copaíba inibiu o crescimento de $C$. gloeosporioides in vitro de forma mais eficiente que o óleo essencial de copaíba.

Termos para indexação: Colletotrichum gloeosporioides; óleo essencial; óleo resina.

\section{ANTHRACNOSE POSTHARVEST CONTROL IN YELLOW PASSION FRUIT WITH APPLICATION OF COPAIBA OIL}

\begin{abstract}
The objective of this study was to evaluate application of the essential oil of copaiba in controlling anthracnose in fruits of passion fruit and compare their fungicidal/fungistatic action in vitro with copaiba oleoresin. In vivo experiment, fruits were inoculated with a spore suspension of $10^{6}$ conidia $\mathrm{mL}^{-1}$ and $1 \%$ Tween 80 , packed in polypropylene trays and placed in a dry incubator at temperature of $25^{\circ} \mathrm{C}$ and $90 \%$ of relative humidity. After 24 hours of inoculation, essential oil was sprayed the following concentrations: $\mathrm{T} 1=0 \mathrm{~mL} \mathrm{~L}^{-1}, \mathrm{~T} 2=0.25 \mathrm{~mL} \mathrm{~L}^{-1}, \mathrm{~T} 3=0.5 \mathrm{~mL} \mathrm{~L}^{-1}, \mathrm{~T} 4=0.75 \mathrm{~mL} \mathrm{~L}^{-1}, \mathrm{~T} 5=1.0 \mathrm{~mL} \mathrm{~L}^{-1}$, and evaluated the mass loss of the fruit, anthracnose severity and number of lesions, both at six days. For the in vitro study, we used culture media potato dextrose agar (PDA) which, after being sterilized by autoclaving $\left(120^{\circ} \mathrm{C}\right)$, was added copaiba oleoresin and essential oil $\left(0,0.5,1.0,1.5\right.$ and $\left.2.0 \mathrm{~mL} \mathrm{~L}^{-1}\right)$. After cooling the PDA culture media was peaked to the center of the plate a mycelial disc of $12.5 \mathrm{~mm}$ diameter of Colletotrichum gloeosporioides and the plates incubated at $25^{\circ} \mathrm{C}$ and $90 \%$ humidity. The measurement of mycelial growth was measured with the aid of analog caliper, after seven days of mycelial growth. The copaiba essential oil, in concentrations of $0.25 \mathrm{~mL} \mathrm{~L}^{-1}$ up to $1.0 \mathrm{~mL} \mathrm{~L}^{-1}$, was not effective in controlling post-harvest of the pathogen in vivo and in mass loss of passion fruits. The copaiba oils inhibited the growth of $C$. gloeosporioides in vitro more efficiently than the copaiba essential oil.
\end{abstract}

Index terms: Colletotrichum gloeosporioides; essential oil; oleoresin.

\footnotetext{
${ }^{1}$ (Trabalho 146-13). Recebido em: 04-04-2013.Parte da dissertação de mestrado do segundo autor apresentada ao programa de Pósgraduação em Agronomia: Produção vegetal da UFAC.

${ }^{2}$ Eng. Agr. Doutor em Fitotecnia, Universidade Federal do Acre. Campus Universitário BR 364 Km 4, Distrito Industrial, CEP 69920900, Rio Branco - Acre. E-mail: selviro2000@yahoo.com.br

${ }^{3}$ Engenheiro Agrônomo, Mestre em Produção Vegetal, SEAP,AC. E-mail: budhamider@hotmail.com

${ }^{4}$ Eng. Agr. Doutor em Fitotecnia, Embrapa Acre, BR 364, Km14, CEP 69900-970, Rio Branco, AC. E-mail: romeu.andrade@embrapa.br ${ }^{5}$ Acadêmica de Agronomia, Universidade Federal do Acre. E-mail: camila_lustosa_morena@hotmail.com

${ }^{6}$ Bióloga, Mestre em Micologia. Universidade Federal do Acre. E-mail: sandraribeiro@hotmail.com.br
} 
O maracujazeiro-amarelo (Passiflora edulis f. flavicarpa Degener) é uma das frutas mais produzidas no País com uma produção, no ano de 2010, de 920.158 toneladas em uma área de 62.019 ha. No Acre, a produção dessa fruta, em 2010, foi de 736 toneladas em 91 ha colhidos, resultando em uma produtividade baixa de $8,08 \mathrm{t} \mathrm{ha}^{-1}$ (IBGE, 2013).

No Brasil, as perdas na pós-colheita de frutas podem chegar a $40 \%$, dependendo da fruta, tipo de colheita, forma de transporte, processamento, armazenamento e da infecção por patógenos (CHITARRA; CHITARRA, 2005; JUNQUEIRA et al., 2003), sendo o fungo Colletotrichum gloeosporioides (PENS) Sacc., causador da antracnose do maracujazeiro e a perda de umidade suas principais causas (SOLINO et al., 2012; SILVA et al., 2009).

A antracnose encontra-se disseminada por todo o Brasil, mas em regiões com umidade e temperaturas altas, como na Amazônia acreana, os prejuízos tendem a ser altos, segundo Fischer et al. (2007), esses fatores são limitantes para a produção de maracujá.

Devido à legislação brasileira proibir o uso de agrotóxicos sintéticos na agricultura orgânica, inclusive em pós-colheita (Lei $\mathrm{N}^{\mathrm{O}} 10.831$, de 23 de dezembro 2003), o controle da antracnose no maracujazeiroamarelo com substâncias naturais pode contribuir com a redução das perdas e a melhoria da qualidade dos frutos (SOLINO et al., 2012).

Há uma vasta gama de produtos naturais no Brasil que são utilizados na medicina tradicional para tratar doenças de todos os tipos, inclusive algumas causadas por fungos. O óleo de copaíba é um destes produtos, sendo largamente utilizado pelos povos da floresta amazônica e empresas de fármacos como antiinflamatório (DEUS et al., 2009; DEUS et al., 2011).

O óleo de copaíba pode ser eficaz no controle de várias espécies fúngicas, como Aspergillus flavus, Aspergillus niger, Aspergillus tamarii, Aspergillus terreus, Candida guilliermandii, Candida tropicallis, Candida parapsilosis, Bipolares sorokiniana, $C$. gloeosporioides (AMORIM et al., 2004; DEUS et al., 2009; OLIVEIRA et al., 2006; SANTOS et al., 2008, SOLINO et al., 2012); inibe o crescimento de bactérias como Escherichia coli, Staphylococcus aureus e Pseudomonas aeruginosa (MENDONÇA; ONOFRE, 2009). Porém, o óleo resina de copaíba em concentrações acima de $0,25 \mathrm{~mL} \mathrm{~L}^{-1}$ provoca alta oleosidade na epiderme dos frutos e odor desagradável, depreciando sua qualidade (SOLINO et al., 2012). Assim, o uso de óleo essencial pode reduzir estes efeitos desagradáveis, pois segundo Deus et al. (2011), é constituído por substâncias mais leves e voláteis, constituindo $75 \%$ do óleo resina, tendo baixa concentração de substâncias resinosas. Seu efeito fungistático pode estar relacionado às concentrações de $\alpha$-copaeno, $\beta$-cariofileno, Trans- $\alpha$-bergamoteno, $\alpha$-humuleno, g-muuroleno e $\beta$-bisaboleno, mantidas após a destilação do óleo resina e no aumento da concentração de óxido de cariofileno.

Portanto, o objetivo deste trabalho foi avaliar a aplicação do óleo essencial de copaíba no controle da antracnose, nos frutos do maracujazeiro-amarelo, e comparar sua ação fungicida/fungistático in vitro com o óleo resina de copaíba.

Foram realizados dois experimentos, sendo o primeiro in vivo, no período de maio a junho de 2012 , para testar doses de óleo essencial, e o segundo in vitro, em agosto de 2012, para comparar a eficiência do óleo essencial e do óleo resina, ambos realizados no laboratório de Fitopatologia da Universidade Federal do Acre - UFAC, em Rio Branco, Acre, Brasil. O inóculo de C. gloesosporioides foi obtido de frutos do maracujá-amarelo, naturalmente infectados.

Para o experimento in vivo, foram utilizados frutos provenientes de produção orgânica do Sítio Ecológico Seridó, localizado no município de Rio Branco, Acre, situado na latitude de $9^{\circ} 53$ ' 16" e longitude de $67^{\circ} 49^{\prime} 11^{\prime \prime}$, na altitude de $170 \mathrm{~m}$.

Foram utilizadas duas etapas: na primeira etapa (pré-teste), doses acima e abaixo de 0,25 mL $\mathrm{L}^{-1}$, definida por Solino et al. (2012) como a que não causa danos ao fruto do maracujá foram testadas $(0$; 0,$10 ; 0,20 ; 0,30$ e $\left.0,40 \mathrm{~mL} \mathrm{~L}^{-1}\right)$. Como a dose máxima testada $\left(0,40 \mathrm{~mL} \mathrm{~L}^{-1}\right)$ não causou danos aos frutos, o segundo experimento foi avaliado com doses de $0 ; 0,25 ; 0,5 ; 0,75$ e 1,0 $\mathrm{mL} \mathrm{L}^{-1}$, diluídos em água destilada acrescida de $30 \mathrm{~mL} \mathrm{~L}^{-1}$ de Tween 80 .

$\mathrm{Na}$ segunda etapa, os frutos foram lavados e higienizados com hipoclorito de sódio a $2 \%$ de cloro livre, enxaguados em água destilada e deixados para secar à temperatura ambiente por 20 minutos. Após a secagem, os frutos foram inoculados com uma suspensão com $10^{6}$ conídios $\mathrm{mL}^{-1}$ e $1 \%$ de Tween 80 , com o auxílio de um pulverizador com capacidade de $500 \mathrm{~mL}$. Esta concentração foi determinada por Dutra (2008) em experimentos com C. gloeosporioides e aferida com o auxílio do hemacitômetro.

Depois de inoculados, os frutos foram acondicionados em bandejas de polipropileno e colocados em câmara incubadora com temperatura de $25^{\circ} \mathrm{C}$ e $90 \%$ de umidade relativa do ar. Passadas 24 horas da inoculação, foram pulverizadas as seguintes doses de óleo essencial de copaíba (tratamentos): T1= $0,0 \mathrm{~mL} \mathrm{~L}^{-1} ; \mathrm{T} 2=0,25 \mathrm{~mL} \mathrm{~L}^{-1}$; T3=0,5 mL L ${ }^{-1}$; $\mathrm{T} 4=$ $0,75 \mathrm{~mL} \mathrm{~L}^{-1}$, e T5=1,0 $\mathrm{mL} \mathrm{L}^{-1}$, acrescidas de Tween 80 na concentração de $30 \mathrm{~mL} \mathrm{~L}^{-1}$. 
As variáveis analisadas no experimento in vivo foram o número de lesões causadas pela antracnose, a severidade da doença e a perda de massa fresca.

A severidade da doença foi avaliada com base na escala diagramática de Fischer et al. (2009), atribuindo-se notas em porcentagem com variações de 1 a $70 \%$.

A perda de massa dos frutos (PMF) de maracujá foi expressa em porcentagem, sendo determinada pela diferença da massa inicial do fruto e a massa final após o armazenamento, utilizando a seguinte expressão:

$$
\mathrm{PMF}=\frac{\mathrm{M}_{\mathrm{i}}-\mathrm{M}_{\mathrm{f}}}{\mathrm{M}_{\mathrm{i}}} \times 100
$$

Em que: $\mathrm{PMF}=$ Perda de massa fresca (\%); $\mathrm{M}_{\mathrm{I}}=\operatorname{Massa}$ inicial $(\mathrm{g}) ; \mathrm{M}_{\mathrm{F}}=\operatorname{Massa}$ final $(\mathrm{g})$.

O experimento foi montado em delineamento inteiramente casualizado, em esquema de parcela subdividida. A parcela foi composta pelo tempo de armazenamento (2, 4 e 6 dias); e as subparcelas, pelas concentrações do óleo essencial, com 8 repetições de três frutos cada.

Todos os dados obtidos foram submetidos ao teste de Shapiro-Wilk, a 5\% de probabilidade, para a verificação das normalidades dos resíduos, e ao de Bartlett, a 5\% de probabilidade, para a verificação da homogeneidade de variâncias.

As variáveis número de lesões de antracnose e perda de massa não atenderam aos pressupostos de normalidade dos resíduos (Shapiro-Wilk) e foram transformados com a equação $\sqrt{\mathrm{x}}$. Posteriormente, os dados passaram pela análise de variância e detectado significância do teste $\mathrm{F}$, foram submetidos à análise de regressão.

Para o experimento in vitro, utilizou-se de BDA como meio de cultura que, após ser esterilizado em autoclave a $120^{\circ} \mathrm{C}$, adicionaram-se óleo essencial de copaíba e óleo resina de copaíba em placas de Petri (20 x $100 \mathrm{~mm}$ ), nas proporções de: $0 ; 0,5 \mathrm{~mL} \mathrm{~L}^{-1} ; 1,0$ $\mathrm{mL} \mathrm{L}^{-1} ; 1,5 \mathrm{~mL} \mathrm{~L}^{-1}$, e $2,0 \mathrm{~mL} \mathrm{~L}^{-1}$. Após o resfriamento do meio de cultura, foi repicada para o centro da placa uma colônia de C. gloeosporioides de 12,5 $\mathrm{mm}^{2}$ de diâmetro e 15 dias de idade, acondicionadas em câmara incubadora a $25^{\circ} \mathrm{C}$ e $90 \%$ de umidade. Após sete dias, realizou-se a aferição do crescimento micelial, determinando-se o diâmetro das colônias com o auxílio de um paquímetro analógico, para o cálculo da área.

O delineamento utilizado foi o inteiramente casualizado, em esquema fatorial $2 \times 5$, sendo o fator principal constituído pelo tipo de óleo; e o fator secundário, pelas concentrações, com sete repetições de uma placa cada.

Todos os dados obtidos foram submetidos ao teste de Shapiro-Wilk $(\mathrm{P}<0,05)$ para a verificação das normalidades dos resíduos e de Bartlett $(\mathrm{P}<0,05)$ para a verificação da homogeneidade de variâncias e, posteriormente, a análise de variância que identificado significância do $\mathrm{F}(\mathrm{P}<0,05)$, procedeu-se à análise de regressão para o fator quantitativo.

Nas análises do experimento in vivo, não foram encontradas diferenças significativas, a $5 \%$ de probabilidade, para severidade e número de lesões (TABELA 1). Houve efeito da interação no tempo de armazenamento e concentração do óleo essencial para perda de massa (FIGURA 1). No experimento in vitro, houve diferença entre os dois fatores avaliados (FIGURA 2).

A aplicação do óleo essencial de copaíba não reduziu a severidade ou o número de lesões de antracnose nos frutos do maracujazeiro-amarelo (TABELA 1). Segundo Solino et al. (2012), o uso de óleo resina de copaíba reduz a severidade in vivo da antracnose do maracujazeiro-amarelo com apenas $0,25 \mathrm{~mL} \mathrm{~L}^{-1}$. Provavelmente, a concentração de sesquiterpenos no óleo essencial, o principal grupo de substâncias responsáveis pelo efeito antifúngico do óleo de copaíba (PIERI et al., 2009), não foi suficiente para promover uma ação fungistática ao C. gloeosporioides inoculado nos frutos de maracujazeiro-amarelo. Provavelmente, o efeito do óleo resina encontrado em menores concentrações, relatados por Solino et al. (2012) no controle do C. gloeosporioides em maracujá e no controle in vitro deste trabalho (Figura 2), tenha ocorrido pelo efeito sinérgico com os diterpenos presentes no óleo resina, que, segundo Pieri et al. (2009), os principais diterpenos do óleo resina são: ácido hardwíckico, colavenol, ácido copaiférico ou copaífero, ácido copaiferólico, ácido calavênico, ácido patagônico, ácido copálico, entre outros.

A perda de massa foi menor nas concentrações de 0,$25 ; 0,50$ e $1,0 \mathrm{~mL} \mathrm{~L}^{-1}$, muito embora todas as concentrações tenham ultrapassado o limite comercial de $8 \%$ de perda de massa já no $2^{\circ}$ dia de pesagem (FIGURA 1), diferentemente do que ocorre com óleo resina, que aumenta a vida útil do maracujáamarelo em até 12 dias, 4 dias a mais que frutos não tratados (SOLINO et al., 2012).

Como a perda de massa é controlada pela atmosfera modificada causada pela formação de películas na epiderme do fruto (SILVA et al., 2009), o uso de óleo essencial de copaíba não promoveu uma película suficientemente espessa para alterar a atmosfera do fruto. Segundo Deus et al. (2011), o óleo 
essencial possui substâncias mais leves e voláteis, $75 \%$ do óleo resina, tendo baixa concentração de substâncias resinosas. Por isso, a película formada não é suficiente para alterar significativamente a troca gasosa no fruto. Sem essa película, o oxigênio atua livremente, causando as alterações físico-químicas pelas quais o fruto passa no período de maturação, com baixo potencial de conservação (CHITARRA; CHITARRA, 2005).

No experimento in vitro, tanto o óleo essencial quanto o óleo resina de copaíba inibiram o crescimento do fungo, sendo o óleo resina mais eficaz que o essencial (Figura 2).

A dose de óleo essencial de copaíba que promoveu o melhor efeito fungistático foi $2,0 \mathrm{~mL} \mathrm{~L}^{-1}$, reduzindo em $88,9 \%$ a área da colônia em relação ao tratamento-controle. Já a melhor dose de óleo resina foi de $1,5 \mathrm{~mL} \mathrm{~L}^{-1}$, reduzindo em $97,1 \%$ a área da colônia do C. gloeosporioides. Esse resultado é semelhante ao encontrado por Solino et al. (2012), em que o percentual de diminuição da área da colônia com óleo resina de copaíba em relação ao controle foi de $44,3 \%$, e relacionam esta inibição da colônia pela presença de diterpenos e sesquiterpenos presentes no óleo resina.

Solino et al. (2012) encontraram correlação positiva entre os dados de severidade da antracnose pelo número de lesões no fruto, em que o aumento do número de lesões/fruto agrava a severidade da doença, tornando-se evidente a necessidade do uso de produtos que atuem na inibição da germinação dos esporos e/ou no estabelecimento das relações patógenos-hospedeiro ou infecção propriamente dita, como óleo de copaíba.
Vários trabalhos corroboram o efeito fungistático do óleo de copaíba em uma série de gêneros, tais como Aspergillus, Candida, Bipolares e Colletotrichum, variando a inibição do crescimento das colônias em função da maior ou menor suscetibilidade da espécie fúngica às substâncias fungistáticas presentes no óleo utilizado (AMORIM et al., 2004; DEUS et al., 2009; DEUS et al., 2011; OLIVEIRA et al., 2006; SOLINO et al., 2012).

O óleo de copaíba é formado principalmente por duas classes de substâncias: os diterpenos e os sesquiterpenos (VEIGA JÚNIOR et al., 2005). Dentro destas duas classes, os sesquiterpenos atuam como agentes antifúngicos, sendo o principal representante o $\beta$-cariofileno (DEUS et al., 2011; PIERI et al., 2009; VEIGA JÚNIOR et al., 2005).

No entanto, o efeito fungistático tanto do óleo resina quanto do óleo essencial de copaíba depende da espécie fúngica que se deseja controlar e podem estar relacionados às concentrações de $\alpha$-copaeno, $\beta$-cariofileno, trans- $\alpha$-bergamoteno, $\alpha$-humuleno, g-muuroleno e $\beta$ - bisaboleno presentes no óleo resina e mantidas no óleo essencial após a destilação, que sofre aumento significativo da concentração de óxido de cariofileno (DEUS et al., 2011).

O óleo essencial de copaíba, nas concentrações de 0,25 a $1,0 \mathrm{~mL} \mathrm{~L}^{-1}$, não é eficaz no controle póscolheita da antracnose do maracujazeiro-amarelo.

O óleo resina de copaíba proporciona maior inibição do crescimento do fungo Colletotrichum gloeosporioides in vitro que seu óleo essencial.

TABELA 1 - Médias das variáveis, severidade e número de lesões causadas por Colletotrichum gloeosporioides em maracujá-amarelo, em função da aplicação de óleo essencial de copaíba. UFAC, Rio Branco-AC, 2012.

\begin{tabular}{ccc}
\hline Concentração $\left(\mathrm{mL} \mathrm{L}^{-1}\right)$ & Severidade $(\%)$ & Número de lesões \\
\hline 0,00 & $44,75^{*}$ & 21,12 \\
0,25 & 33,75 & 25,62 \\
0,50 & 40,62 & 27,00 \\
0,75 & 49,25 & 22,75 \\
1,00 & 36,12 & 25,12 \\
\hline CV (\%) & 51,19 & 17,98 \\
Média & 40,9 & 24,32 \\
\hline
\end{tabular}

* Não houve efeito significativo das doses testada, pelo teste $\mathrm{F}(\mathrm{P}>0,05)$. 


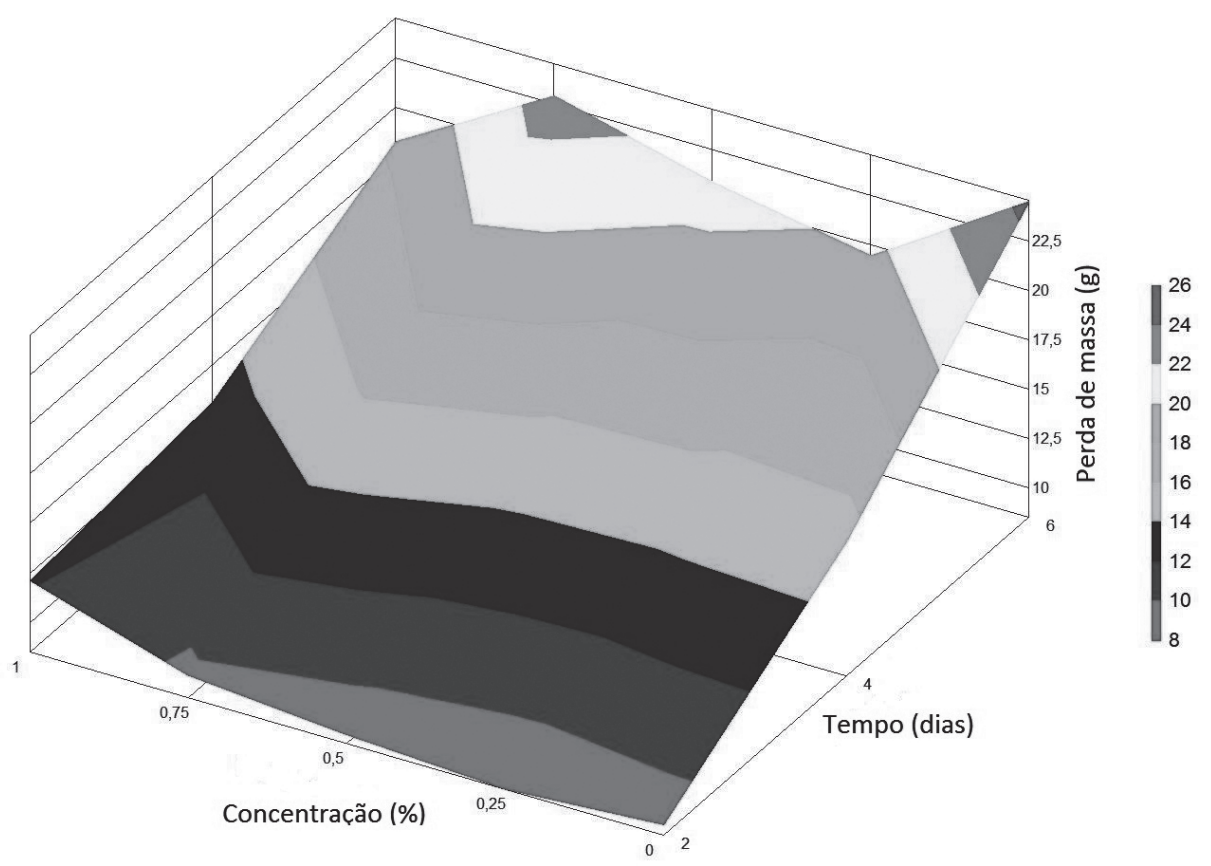

FIGURA 1 - Perda de massa de frutos do maracujazeiro- amarelo em função da concentração da aplicação de óleo essencial de copaíba e do tempo. UFAC, Rio Branco-AC, 2012.

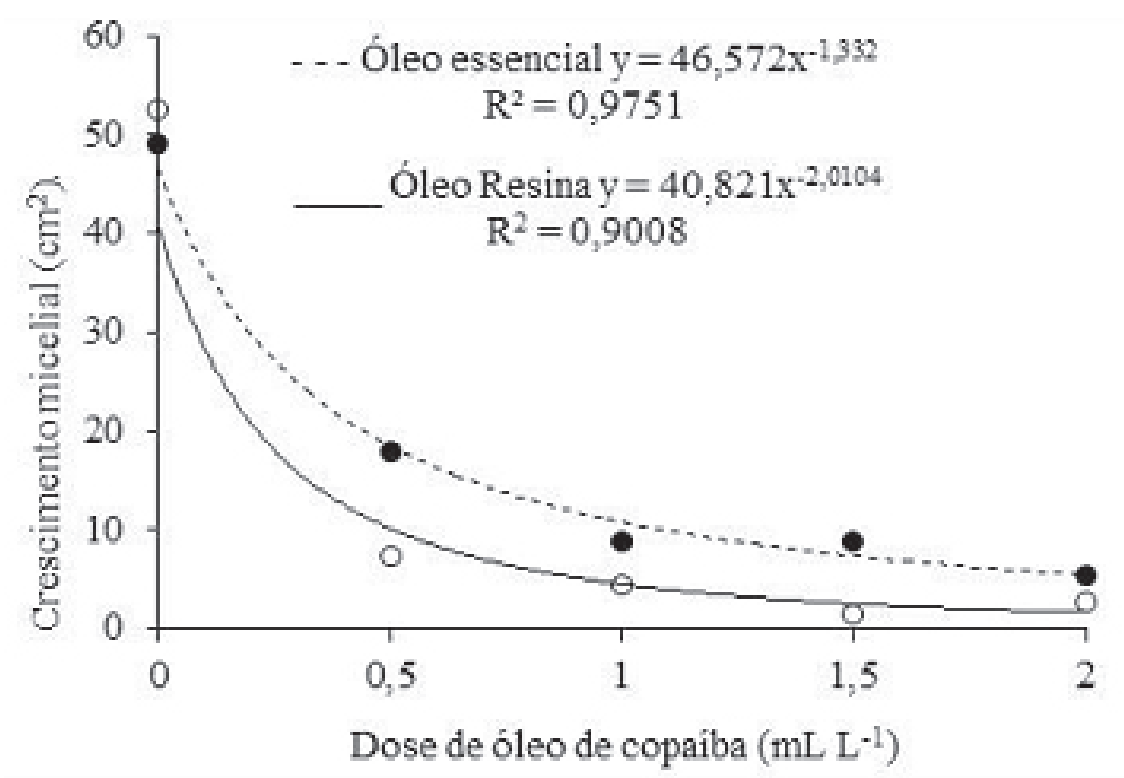

FIGURA 2 - Inibição do crescimento micelial do fungo Colletotrichum gloeosporioides in vitro em função da aplicação de óleo essencial e óleo resina de copaíba. UFAC, Rio Branco-AC, 2012. 


\section{REFERÊNCIAS}

AMORIM, A. C. L.; CARDOSO, M. das G.; PINTO, J. E. B. P.; SOUZA, P. E. de; DELÚ FILHO, N. Fungitoxic activity avaliation of the hexane and metanol extracts of copaiba plant leaves Capaifera langsforffi Desfon. Ciência e Agrotecnologia, Lavras, v. 28, n.2, p. 314-322, 2004.

Chitarra, M. I. F.; ChitARrA, A. B. Póscolheita de frutas e hortaliças: fisiologia e manuseio. 2. ed. rev. amp. Lavras: Universidade Federal de Lavras, 2005. 785p.

DEUS, R. J. A.; ALVES, C. N.; ARRUDA, M. S. P. Avaliação do efeito antifúngico do óleo resina e do óleo essencial de copaíba (Copaifera multijuga Hayne). Revista Brasileira de Plantas Medicinais, Botucatu, v.13, n.1, p.1-7, 2011.

DEUS, R. J.A.; CARVALHO, A. S. C.; BANNA, D. A. D. S.; ARRUDA, M. S. P.; ALVES, C. N.; SANTOS, A. S. Efeito fungitóxico in vitro do óleo resina e do óleo essencial de copaíba (Copaifera multijuga Hayne). Revista Brasileira de Plantas Medicinais, Botucatu, v. 11, n. 3, p. 347-353, 2009.

DUTRA, J. B. Controle da Antracnose (Colletotrichum gloeosporioides) pós-colheita do maracujá-amarelo (Passiflora edulis f. flavicarpa) por aplicações de fosfitos, água quente e 1-metilciclopropeno. 2008. 151 f. Dissertação (Mestrado em Fitopatologia) -Universidade de Brasília, Brasília, 2008.

FISCHER, I. H.;ALVES, S. A. M.; ALMEIDA, A. M. de; ARRUDA, M. C. de; BERTANI, R. N.; GARCIA, M. J. de M. Elaboração e validação de escala diagramática para a quantificação da severidade da antracnose em frutos de maracujá-amarelo. Summa Phytopathologica, Botucatu, v. 35, n. 3, p. 226-228, 2009.

FISCHER, I. H.; ARRUDA, M. C. de; ALMEIDA, A. M. de; GARCIA, M. J. de M.; JERONIMO, E. M.; PINOTI, R. N.; BERTANI, R. N. de A. Doenças e características físicas e químicas pós-colheita em maracujá-amarelo de cultivo convencional e orgânico no centro-oeste paulista. Revista Brasileira de Fruticultura, Jaboticabal, v. 29, n. 2, p. 254-259, 2007.

IBGE- Instituto Brasileiro de Geografia e Estatística. Produção agrícola municipal - culturas temporárias e permanentes. Produção Agrícola Municipal, Rio de Janeiro, v. 37, p.1-91, 2010. Disponível em: < http://www.ibge.gov.br/home/estatistica/economia/ pam/2010/PAM2010 Publicacao completa.pdf $>$. Acesso em: 30 ago. 2013.
JUNQUEIRA, N. T. V.; ANSELMO, R. M.; PINTO, A. C. Q.; RAMOS, V. H. V.; PEREIRA, A. V.; NASCIMENTO, A. C. Severidade da antracnose e perda de matéria fresca de frutos de dez procedências de maracujazeiro-doce (Passiflora alata Dryander) em dois ambientes de armazenamento. Revista Brasileira de Fruticultura, Jaboticabal, v. 25, n. 1, p. 71-73, 2003.

MENDONÇA, D. E.; ONOFRE, S. B. Atividade antimicrobiana do óleo-resina produzido pela copaíba - Copaifera multijuga Hayne (Leguminosae). Revista Brasileira de Farmacognosia, João Pessoa, v.19, p.577-581, 2009.

OLIVEIRA, E. C. P.; LAMEIRA, O. A.; BARROS, P. L. C. de; POLTRONIERI, L. S. Avaliação do óleo de copaíba (Copaifera spp.) na inibição do crescimento micelial in vitro de fitopatógenos. Revista Ciências Agrárias. Belém, n. 46, p. 53-63, 2006.

PIERI, F. A.; MUSSI, M. C.; MOREIRA, M. A. S. Óleo de copaíba (Copaifera sp.): histórico, extração, aplicações industriais e propriedades medicinais. Revista Brasileira de Plantas Medicinais, Botucatu, v. 11, n. 3, p. 465-472, 2009.

SANTOS, A. O. dos; UEDA-NAKAMURA, T.;DIAS FILHO, B. P.; VEIGA JÚNIOR, V. F.; PINTO, A. C.; NAKAMURA, C. V. Antimicrobial activity of Brazilian copaiba oils obtained from different species of the Copaifera genus. Memórias do Instituto Oswaldo Cruz, Rio de Janeiro, v.103, n.3, p.277-281, 2008.

SILVA, L. J. B. da; SOUZA, M. L. de; ARAÚJO NETO, S. E. de; MORAIS, A. P. Revestimentos alternativos na conservação pós-colheita de maracujáamarelo. Revista Brasileira de Fruticultura, Jaboticabal, v. 31, n. 4, p. 995-1.003, 2009.

SOLINO, A. J. da S.; ARAÚJO NETO, S. E. de, SILVA, A. L. N. da; SOUZA, A. M. A. de. Severidade da antracnose e qualidade dos frutos de maracujá-amarelo tratados com produtos naturais em pós-colheita. Revista Brasileira de Fruticultura, Jaboticabal, v.34, p.57-66, 2012.

VEIGA JÚNIOR, V. F.; PINTO, A. C.; MACIEL, M. A. M. Plantas medicinais: cura segura? Química nova, São Paulo, v.28, n.3, p.519-28, 2005. 